\title{
Rapid emergence of resistance to antiretroviral treatment after undisclosed prior exposure: A case report
}

\begin{tabular}{|c|c|}
\hline \multicolumn{2}{|c|}{ 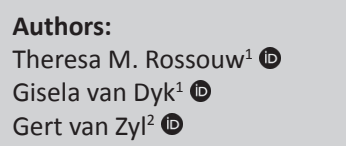 } \\
\hline \multicolumn{2}{|c|}{$\begin{array}{l}\text { Affiliations: } \\
{ }^{1} \text { Department of Immunology, } \\
\text { University of Pretoria, } \\
\text { Pretoria, South Africa }\end{array}$} \\
\hline \multicolumn{2}{|c|}{$\begin{array}{l}{ }^{2} \text { Division of Medical Virology, } \\
\text { Stellenbosch University and } \\
\text { National Health Laboratory } \\
\text { Service, Bellville, South Africa }\end{array}$} \\
\hline \multicolumn{2}{|c|}{$\begin{array}{l}\text { Corresponding author: } \\
\text { Theresa Rossouw, } \\
\text { theresa.rossouw@up.ac.za }\end{array}$} \\
\hline \multicolumn{2}{|c|}{$\begin{array}{l}\text { Dates: } \\
\text { Received: } 08 \text { Mar. } 2019 \\
\text { Accepted: } 28 \text { Mar. } 2019 \\
\text { Published: } 30 \text { July } 2019\end{array}$} \\
\hline \multicolumn{2}{|c|}{$\begin{array}{l}\text { How to cite this article: } \\
\text { Rossouw TM, Van Dyk G, } \\
\text { Van Zyl G. Rapid emergence } \\
\text { of resistance to antiretroviral } \\
\text { treatment after undisclosed } \\
\text { prior exposure: A case report. } \\
\text { S Afr J HIV Med. 2019;20(1), } \\
\text { a965. https://doi.org/10.4102/ } \\
\text { sajhivmed.v20i1.965 }\end{array}$} \\
\hline \multicolumn{2}{|c|}{$\begin{array}{l}\text { Copyright: } \\
\text { (c) 2019. The Authors. } \\
\text { Licensee: AOSIS. This wo } \\
\text { is licensed under the } \\
\text { Creative Commons } \\
\text { Attribution License. }\end{array}$} \\
\hline \multicolumn{2}{|l|}{ Read online: } \\
\hline 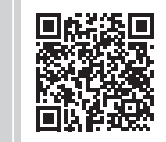 & $\begin{array}{l}\text { Scan this QR } \\
\text { code with your } \\
\text { smart phone or } \\
\text { mobile device } \\
\text { to read online. }\end{array}$ \\
\hline
\end{tabular}

Introduction: Patients who disengaged from care may present as therapy naïve for antiretroviral treatment (ART) initiation at a different site, without being recognised as being at an increased risk of rapid treatment failure and HIV drug resistance.

Patient presentation: A 43-year-old woman, who gave no prior history of ART, was initiated on a standard first-line regimen of TDF, FTC and EFV. She had a poor response to treatment with evidence of treatment failure at 12 months.

Management and outcome: HIV-1 drug resistance tests showed no pre-treatment HIVDR mutations, but revealed high-level drug resistance to all component drugs at 12 months. On investigation, viral load (VL) was recorded in 2012 and 2013, providing evidence of prior ART use.

Conclusion: Linkage of patient therapy and laboratory information to unique patient identifiers may allow health-care workers to identify patients who previously received ART and disengaged from care. This will enable differentiated care when these patients reinitiate ART, which should involve expedited VL testing and more rapid transition to definitive second-line ART.

Keywords: HIV drug resistance; Antiretroviral therapy; Undisclosed prior treatment.

\section{Introduction}

HIV drug resistance (HIVDR) is a major public health concern, especially in the context of a large treatment programme. Patients who disengage from care and then return to the health-care system without disclosing previous antiretroviral therapy (ART) are at increased risk of having pre-existing drug resistance. Unfortunately, patients rarely report prior ART use, and health-care workers do not routinely ask and record this. All drugs in the current first-line regimen (TDF, FTC and EFV) have low genetic barriers, and hence, one or two mutations lead to diminished activity, which can affect entire drug classes. HIV drug resistance testing is not currently available in the South African public sector for patients initiating or failing first-line ART. Here we describe a case of a patient with undisclosed prior exposure to ART who had a complex HIVDR pattern at treatment failure and highlight potential risk factors for rapid HIVDR emergence.

\section{Case description}

A 43-year-old woman presented to a clinic in Tshwane, South Africa, on 23 July 2014. She tested HIV-positive and had a CD4 count of 14 cells $/ \mu$ L and HIV-1 viral load (VL) of 560000 copies / mL. She gave no prior history of ART and was initiated on a first-line regimen of TDF, FTC and EFV on 06 August 2014. She attended all her visits on time and reported good adherence, but had a poor response after 12 months of treatment: CD4 53 cells $/ \mu \mathrm{L}$ and VL 186000 copies $/ \mathrm{mL}$. The 6-month VL had not been performed. As part of a research project (ethics approval 469/2013), she had a drug resistance test (DRT) with a validated in-house Sanger-based sequencing method ${ }^{1}$ before the initiation of ART, which showed no HIVDR mutations, and again after 12 months, which revealed six nucleoside/nucleotide reverse transcriptase inhibitor (NRTI) and three nonnucleoside reverse transcriptase inhibitor (NNRTI) mutations (Tables 1 and 2). A search of the NHLS database for evidence of prior HIV-related testing revealed two VL results (2012 and 2013), which precede her ART-initiation date (Figure 1).

\section{Ethical consideration}

This study was part of a research project that had been approved by the Research Ethics Committee of the Faculty of Health Sciences of the University of Pretoria (ethics approval number 469/2013). 
TABLE 1: Drug resistance report at 12 months.

\section{Drug resistance interpretation: $\mathrm{RT}$}

NRTI Resistance Mutations

NNRTI Resistance Mutations

A62V, K65R, V75I, Y115F, M184V, K219E

Other Mutations

L100I, K103N

Nucleoside reverse transcriptase inhibitors

abacavir (ABC)

zidovudine (AZT)

emtricitabine (FTC)

lamivudine (3TC)

tenofovir (TDF)

Non-nucleoside reverse transcriptase inhibitors

doravirine (DOR)

efavirenz (EFV)

etravirine (ETR)

nevirapine (NVP)

rilpivirine (RPV)
v90I

High-level Resistance

Susceptible

High-level Resistance

High-level Resistance

High-level Resistance

Intermediate Resistance

High-level Resistance

Intermediate Resistance

High-level Resistance
High-level Resistance

Source: Adapted from the Stanford database ${ }^{2}$

Note: The drug resistance profile reveals a mixed pattern consisting of the classic XTC-related mutation, M184V/I; two TDF-associated mutations, Y115F and K65R; one accessory thymidine-associated mutation (TAM) related to decreased susceptibility to d4T and AZT namely $\mathrm{K} 219 \mathrm{Q} / \mathrm{E}$; and two accessory mutations, A62V and V75I, that have been described with $\mathrm{K} 65 \mathrm{R}^{3}$ but mostly occur in combination with the multi-NRTI resistance mutation Q151M. The two NNRTI mutations, L100I and K103N, give broad-spectrum resistance to the NNRTI class, including intermediate resistance to the second-seneration NNRTIs, while Vio is a polymorphic accessory mutation selected by NNRTIs and is associated with reduction in susceptibility to this class. ${ }^{2}$

TABLE 2: Mutation-penalty score for the reverse transcriptase inhibitors.

Mutation Scoring: RT

\begin{tabular}{lccccc}
\hline NRTI & ABC & AZT & FTC & 3TC & TDF \\
\hline A62V & 5 & 5 & 5 & 5 & 5 \\
K65R & 45 & -15 & 30 & 30 & 60 \\
V75I & 5 & 5 & 5 & 5 & 5 \\
Y115F & 60 & 0 & 0 & 0 & 15 \\
M184V & 15 & -10 & 60 & 60 & -10 \\
K219E & 5 & 10 & 0 & 0 & 5 \\
\hline Total & $\mathbf{1 3 5}$ & $\mathbf{- 5}$ & $\mathbf{1 0 0}$ & $\mathbf{1 0 0}$ & $\mathbf{8 0}$ \\
\hline NNRTI & DOR & EFV & ETR & NVP & RPV \\
\hline L100I & 15 & 60 & 30 & 60 & 60 \\
L100I + K103N & 15 & 0 & 0 & 0 & 0 \\
K103N & 0 & 60 & 0 & 60 & 0 \\
\hline Total & $\mathbf{3 0}$ & $\mathbf{1 2 0}$ & $\mathbf{3 0}$ & $\mathbf{1 2 0}$ & $\mathbf{6 0}$ \\
\hline
\end{tabular}

Source: Adapted from the Stanford database ${ }^{2}$

Note: This combination of mutations leaves only AZT as a viable NRTI.

RT, reverse transcriptase; NRTI, nucleoside/nucleotide reverse transcriptase inhibitors $A B C$, abacavir; AZT, zidovudine; FTC, emtricitabine; 3TC, lamivudine; TDF, tenofovir disoproxi fumarate; NNRTI, non-nucleoside reverse transcriptase inhibitor; DOR, doravirine EFV, efavirenz; ETR, etravirine; NVP, nevirapine; RPV, rilpivirine.

\section{Discussion}

This case study describes the rapid emergence of high-level, dual-class HIVDR in a patient with undisclosed prior ART use. Having nine reverse transcriptase mutations within 12 months is much faster than the reported rate of emergence. ${ }^{4}$ This together with the unsuppressed VL during 2012 and 2013 suggests prior HIVDR mutation selection, which waned to below the detection threshold of population sequencing $( \pm 20 \%)$ when DRT was performed in 2014. Thereafter, it rapidly re-emerged upon reintroduction of ART.

Prior undisclosed use of ART is a common problem, requiring vigilance, especially in health sectors where patients are mobile and do not have unique identifiers, as is the case in South Africa. Recent data from Botswana showed that 136/951 (14\%) HIV-infected participants who reported no

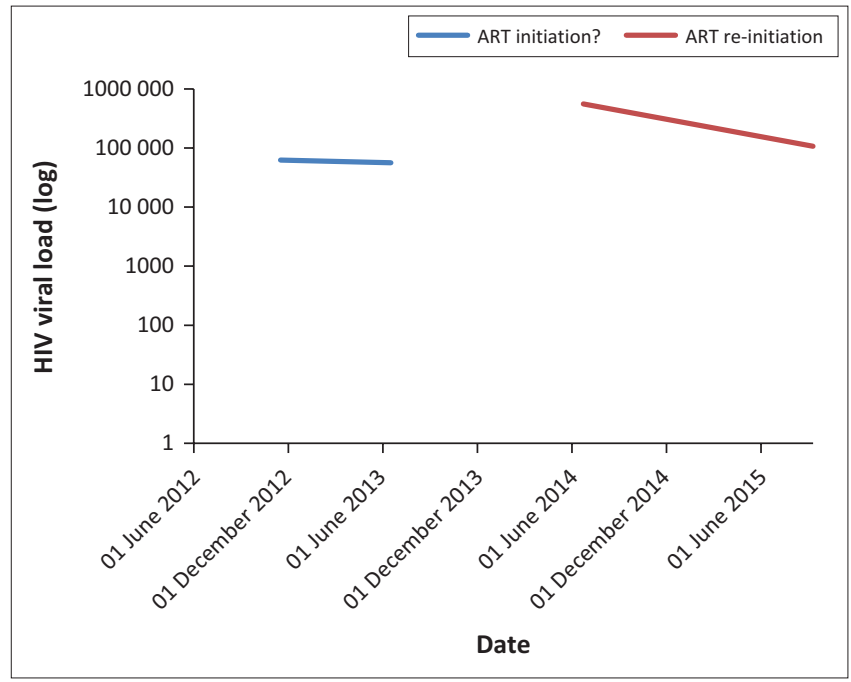

ART, antiretroviral therapy.

FIGURE 1: HIV viral load results over time.

prior ART use had a baseline VL of $<400$ copies $/ \mathrm{mL}$, and of these, 39\% had detectable ART levels in plasma. ${ }^{5}$ A study from Khayelitsha reported that $23 \%$ of patients disengaged from care for at least 6 months and that $\sim 50 \%$ of these returned to care in the medium term. ${ }^{6}$ Almost $1 / 3$ of adults restarting first-line ART with prior ART exposure harbour resistant virus with women twice as likely as men to have resistance because of previous ART exposure during pregnancy. ${ }^{7}$ Patients with multiple treatment interruptions and/or pre-treatment drug resistance (PDR) are at an increased risk of virological failure. . $^{8,910,11}$ This patient had seven different laboratory numbers, making linking her previous results complicated. Patients with prior ART may benefit from differentiated care with specialised adherence support, an early $\mathrm{VL}^{12}$ (at 4 months), DRT in case of a suboptimal VL response and rapid change to a second-line regimen. The absence of a 6-month VL in this patient made prompt action impossible. She had a number of risk factors for treatment failure, namely previous ART, high VL and previous adherence issues, which could have alerted the astute clinician had this information been available.

\section{Acknowledgements}

The authors would like to thank Sr Eileen Thompson for assisting with patient recruitment.

\section{Competing interests}

The authors declare that they have no financial or personal relationship(s) that may have inappropriately influenced them in writing this article.

\section{Authors' contributions}

G.v.D. performed the laboratory work, namely Sanger sequencing, and interpretation of the results; T.M.R. accessed and interpreted the clinical information and prepared the first draft of the manuscript; G.v.Z. assisted with the interpretation of the genotype. All authors contributed to and proofread the final manuscript. 


\section{Funding Information}

This work was financially supported by the National Research Foundation (NRF) (grant number 87876) and the University of Pretoria and National Health Laboratory Service (NHLS) Research Trust (grant number 94447).

\section{Data availability statement}

The clinical and genotypic data will be made available on request.

\section{Disclaimer}

The views expressed in the article are those of the authors and not an official position of the institution or funder.

\section{References}

1. Manasa J, Katzenstein D, Cassol S, Newell ML, De Oliveira T, Southern Africa Treatment And Resistance Network (SATuRN). Primary drug resistance in South Africa: Data from 10 years of surveys. AIDS Res Hum Retroviruses. 2012;28(6) 558-565. https://doi.org/10.1089/AID.2011.0284

2. LiuTF, Shafer RW. Web resources for HIV type 1 genotypic-resistance test interpretation. Clin Infect Dis. 2006;42(11):1608-1618. https://doi.org/10.1086/503914

3. Parikh UM, Barnas DC, Faruki H, Mellors JW. Antagonism between the HIV-1 reverse-transcriptase mutation $\mathrm{K} 65 \mathrm{R}$ and thymidine-analogue mutations at the genomic level. J Infect Dis. 2006;194(5):651-660. https://doi.org/10.1086/505711
4. Rossouw TM, Nieuwoudt M, Manasa J, et al. HIV drug resistance levels in adults failing first line antiretroviral therapy in urban and rural settings in South Africa. HIV Med. 2017;18(2):104-114. https://doi.org/10.1111/hiv.12400

5. Moyo S, Gaseitsiwe S, Powis KM, et al. Undisclosed antiretroviral drug use in Botswana: Implication for national estimates. AIDS 2018;32(11):1543-1546. https://doi.org/10.1097/QAD.0000000000001862

6. Kaplan SR, Oosthuizen C, Stinson K, et al. Contemporary disengagement from antiretroviral therapy in Khayelitsha, South Africa: A cohort study. PLoS Med. 2017;14(11):e1002407. https://doi.org/10.1371/journal.pmed. 1002407

7. WHO, CDC, Global Fund. HIV drug resistance report 2017 [homepage on the Internet]. Geneva: World Health Organization; 2017 [cited 2019 Feb 28]. Licence: CC BY-NC-SA 3.0 IGO. Available from: https://apps.who.int/iris/bitstream/ handle/10665/255896/9789241512831-eng.pdf?sequence=1

8. Kantor R, Smeaton L, Vardhanabhuti S, et al. Pretreatment HIV drug resistance and HIV-1 subtype care independently associated with virologic failure: Results from the multinational PEARLS (ACTG A5175) clinical trial. Clin Infect Dis. 2015;60(10):1541-1549. https://doi.org/10.1093/cid/civ102

9. Hamers RL, Schuurman R, Sigaloff KC, et al. Effect of pretreatment HIV-1 drug resistance on immunological, virological, and drug-resistance outcomes of firstline antiretroviral treatment in sub-Saharan Africa: A multicentre cohort study. Lancet Infect Dis. 2012;12(4):307-317. https://doi.org/10.1016/S1473-3099(11) 70255-9

10. Parienti J-J, Massari V, Descamps D, et al. Predictors of virologic failure and resistance in HIV-infected patients treated with nevirapine- or efavirenz-based antiretroviral therapy Clin Infect Dis [serial online]. 2004 [cited 2019 Mar 01];38(9):1311-1316. Available from: https://academic-oup-com.ez.sun ac.za/cid/article/38/9/1311/317940

11. Oyugi $\mathrm{JH}$, Byakika-Tusiime J, Ragland $\mathrm{K}$, et al. Treatment interruptions predict resistance in HIV-positive individuals purchasing fixed-dose combination antiretroviral therapy in Kampala, Uganda. AIDS. 2007;21(8):965-971. https:// doi.org/10.1097/QAD.0b013e32802e6bfa

12. Grimsrud A, Barnabas RV, Ehrenkranz P, Ford N. Evidence for scale up: The differentiated care research agenda. J Int AIDS Soc. 2017;20(Suppl 4):22024. https://doi.org/10.7448/IAS.20.5.22024 